\title{
FEBRE DE ORIGEM INDETERMINADA
}

\author{
Vicente Amato Neto *
}

A denominada febre de origem indeterminada, obscura ou desconhecida, ainda referida como febre prolongada ou de diagnóstico difícil, representa sem dúvida fascinante problema de diagnóstico diferenicial. Freqüentemente, ocorre como questão merecedora de judiciosas considerações no âmbito da Medicina Interna e, especialmente nos últimos anos, tem sido objeto de avaliações e revisões.

Casos de febre de origem indeterminada são, na época atual, aparentemente mais comuns. Para explicar essa circunstância, alguns autores, como Bertrand, apontam determinados motivos, tais como o uso abusivo de antibióticos, de corticosteróides e de outras drogas, com o possível "camuflamento" da febre durante certo tempo, como também lembram os erros inelutáveis de laboratório e a precária coordenação das investigações relativas a um paciente.

A conceituação de febre de origem indeterminada é ainda vaga e, no que concerne à duração e nível de hipertermia, como à distinção entre temperatura corpórea normal e alterada, não houve definição final por parte dos estudiosos do assunto, para a devida configuração do problema.

Têm sido apresentadas, todavia, tentativas de definição ou conceituação de febre de origem indeterminada, baseadas em diferentes critérios.

Apesar de não contarmos com definição aceita de forma unânime ou considerada oficial, podemos lembrar as caracteriza- ções formuladas por vários autores, em estudos freqüentemente de caráter retrospectivo.

Para Petersdorf e Beeson, febre de origem indeterminada é a que persiste durante três ou mais semanas, em níveis de $38,3^{\circ} \mathrm{C}$ por várias vêzes, permanecendo incerto o diagnóstico depois de sete dias de investigação hospitalar.

Sheon e Van Ommen, por seu turno, estabeleceram as seguintes premissas: a) temperatura corpórea acima de $38,0^{\circ} \mathrm{C}$; b) duração maior do que três semanas; c) idade do doente superior a 16 anos; d) diagnóstico não sugerido pelos sintomas e sinais, através da anamnese e exame físico e, ainda, de análises hematológica, de urina e radiográfica do tórax.

Segundo Bertrand, trata-se de febre com pelo menos um mês de duração, đesacompanhada de sintomas ou de sinais clíni$\cos$ e, por êsse motivo, qualificada como "nua", podendo também estar presentes manifestações que não conduzem a esclarecimento em exames clínicos ou paraclínicos rotineiros.

Febre de origem indeterminada, de acôrdo com Geraci e colaboradores, é contínua e persistente por mais de duas semanas ou, então apresenta-se intermitente, durante fases mais longas, não tendo causa reconhecida após cuidadosa e reiterada anamnese, exame físico e amplas investigações laboratoriais.

Gower, finalmente, reuniu e salientou três modalidades de acôrdo com as quais é caracterizada a febre de origem indeter-

* Livre-docente de Clínica de Doenças Tropicais e Infectuosas, da Faculdade de Medicina da Universidade de São Paulo. Medico-chefe do Serviço de Doenças Transmissíveis, do .Hospital do Servidor Público Estadual de Säo Paulo. Professor de Doenças Transmissiveis, da Faculdade de Medicina da Universidade de Campinas. Membro do Instituto de Medicina Tropical de São Paulo. 
minada: a) elevação térmica como feição principal da doença e impossibilidade de estabelecer diagnóstico do início do período de observação, consubstanciando os casos habitualmente citados como de processos febris de naturezas a serem esclarecidas; b) persistência da hipertermia no decurso da doença e diagnóstico não firmado, correspondendo mais precisamente aos problemas de febre de origem indeterminada, conforme o consenso mais habitualmente aceito; c) temperatura anormal mas pouco elevada e ausência de lesões orgânicas demonstráveis levando comumente à rotulagem dos casos como de febre psicogênicas e de hipertermia essencial, por exemplo. A rubrica de febre de origem indeterminada mais apropriadamente caberia ao segundo tipo citado, desde que múltiplos e convenientes processos de diagnóstico e período de tempo suficiente para satisfatória observação e apropriado seguimento tenham sido tentados e ocorrido.

Apreciação concernente ao assunto foi recentamente realizada por Magaldi, na Clínica de Doenças Tropicais e Infectuosas, do Hospital das Clínicas da Faculdade de Medicina da Universidade de são Paulo. Mereceram análises os prontuários de pacientes com processos febris de tipos obscuros, internados durante o período de dois anos. Três finalidades fundamentais nortearam essa revisão, conforme referiu Magaldi:(1) verificar, em nosso meio, a existência dessas febres e os recursos de que dispomos e empregamos, atualmente, para atingir um diagnóstico definitivo; 2) proporcionar uma casuística, ainda que não extensa, que pudesse refletir alguns quadros mórbidos mais pertinentes ao nosso meio tropical e subtropical; 3) tentar uma conceituação de febre de origem indeterminada, baseada em um critério prèviamente adotado e na análise dos casos por êle selecionados."

Para a escolha dos casos, diretriz bastante simples foi estabelecida: febre de duração igual ou maior do que 21 dias. Dessa forma, houve tentativa no sentido de identificar situações que realmente ofereceram óbices à concretização de diagnósticos ou que permaneceram sem esclarecimento.

A análise dessas informações fornecidas por Magaldi mostrou que, no que diz res- peito aos 102 casos selecionados, o diagnóstico correspondente a 92 pôde ser estabelecido; quando aos demais dez doentes $(9,8 \%)$, o mesmo não sucedeu. Muitas vêzes, as naturezas dos processos em causa ficaram esclarecidas durante os primeiros 15 dias de internação e, nesse grupo de 69 pacientes, a causa da febre foi detectada em menos de 48 horas. Ao contrário, a revisāo dos prontuários dos outros 23 indivíduos revelou que prazos superiores ao citado tornaram-se necessários, sendo que, relativamente a dez entre êles, um ou dois meses decorreram até que os diagnósticos fôssem obtidos; três doentes aguardaram, por seu turno, mais do que 90 dias para que as afeções que os acometiam ficassem conhecidas.

Com base na presença ou ausência de sinais de localização, nas manifestações clínicas de aparecimento precoce ou tardio, no decurso típico ou não de doença comum, nas associações mórbidas ausentes ou presentes, na dispensa ou necessidade de exames mais especializados e, flinalmente, no período de tempo maior ou menor consumido até o reconhecimento do tipo de processo mórbido, Magaldi separou os casos referidos em três categorias: a) diagnóstico considerado fácil - $75(73,5 \%)$; b) de diagnóstico considerado difícil - $17(16,6 \%)$; c) sem diagtico $-10(9,8 \%)$.

o estudo em aprêço levou a uma conceituação, pelo menos provisória, de febre de origem indeterminada: processo de duração superior a 21 dias, em geral sem sintomas ou sinais de localização, sendo inconclusivos os exames subsidiários rotineiros e com necessidade de período de tempo maior do que 15 dias para estabelecimento do diagnóstico de doença orgânica, por meio de utilização de provas complementares mais especializadas, em regime de internação. Sob o rótulo de febre de origem indeterminada é possível incluir também doença febril com essas características lembradas, mas de causa não determinada após fase de investigação hospitalar e com disponibilidade de convenientes recursos.

Evidentemente, conceito definitivo mais fàcilmente advirá de estudos prospectivos, nos quais a padronização das observações clínicas, dos esquemas propedêuticos e do 
seguimento evolutivo dos pacientes possibilite, inclusive, análise estatística da questão.

Como já foi assinalado, múltiplas conceituações de febre de origem indeterminada têm sido indicadas e englobam parâmetros, detalhes e especificações não uniformes. Assim, as idades dos pacientes são variáveis, como também os graus de elevação térmica e durações dos períodos febris afiguram-se heterogêneos, entre os critérios aceitos como norteadores. A : $n$ tensidade da febre não é, na verdade, elemento orientador importante e a duração dessa manifestação deve ser judiciosamente considerada; por exemplo, Magaldi separou casos em relação aos quais não houvera definição diagnóstica durante três semanas, mas logo após a internação ocorreram rápidos esclarecimentos, muitas vêzes de maneiras facílimas.

Consideramos criterioso caracterizar como de febre de origem indeterminada os casos em que manifestação febril, de qualquer intensidade, não correspondeu a esclarecimento diagnóstico após 15 dias, apesar da concretização de intensiva e adequada investigação.

Bàsicamente, são três os tipos de pacientes que se apresentam buscando esclarecimento para seus problemas febris:

a) indivíduos que, submetidos a cuidadosa observação, já precocemente têm as naturezas das afecções que os acometem suspeitadas, surgindo ràpidamente os esclarecimentos diagnósticos;

b) irdivicuos com comprometimento orgânico evidente e que, mesmo depois de investigação bem conduzida, durante duas semanas, ficam à espera de resolução diagnóstica definitiva, sendo as elevações térmicas acentuadas ou não, em tais circunstâncias;

c) indivíduos em condições semelhantes às referidas no item anterior, mas com alterações térmicas discretas e sem modificações orgânicas notórias e expressivas.

Para casos como os últimos referidos são usados, com freqüência, os rótulos de febre idiopática, hipertermia essencial, febre psicogênica e febre por drogas. Lògicamente, é preciso agir com muita prudência e cautela antes de estabelecer essas em geral perigosas qualificações.
A literatura médica indica taxas de $6 \%$ a $67 \%$, correspondentes a faltas de elucidações de febre de origem indeterminada. A casuística de Petersdorf e Beeson exemplifica bem algumas facêtas ligadas à averiguação dessas questões. Assim, a simples adoção de conduta correta e a paralela disponibilidade de recursos levou à efetivação do điagnóstico em relação a grande número de casos, valendo ressaltar que, a propósito, são muito úteis a experiência e preparo profissional dos médicos; entretanto, no grupo referido como miscelânea, estão indicados problemas de resolução esclarecedora realmente difícil, como as doenças de Weber-Christian e periódica, habitualmente esquecidas ou pouco inspiradoras em suas fases de pobreza no que concerne à presença de dados mais característicos.

Às vêzes, as dificuldades inerentes a determinados casos são, sem dúvida, patentes e claramente compreensíveis. Por exemplo, mielofibrose e outras afeç̧ōes decorrem de esclarecimentos propiciados geralmente por autópsias. Até mesmo curiosidades, mais do que aspectos de caráter prático, ficam evidenciadas em certas circunstâncias; a essa categoria pertencia paciente com febre há muito tempo e que veio a morrer em virtude de acidente automobilístico, tondo o exame necroscópico, segundo pôde ser relatado, mostrado aneurisma que exercia influência em relação ao centro termorregulador.

Diversos fatôres podem contribuir para que o problema relativo à febre de origem indeterminada assuma maior ou menor relevância; entre êles, lembramos alguns que consideramos bastante influentes: a) o preparo profissional dos médicos; b) a disponibilidade de recursos relativos à execução de exames subsidiários; c) a circunstância de ficarem evidentes, no decurso de certas afecções, aspectos incomuns, o que determina dificuldades diagnósticas; d) a possibilidade de realizar, em face a determinados casos, observação judiciosa durante suficiente pertodo de tempo; e) a ocorrência de doença de caracterização recente e ainda não amplamente divulgada através da literatura especializada; f) a concomitância de mais de uma afecção; g) os aspectos médicos regionais, ou melhor, o devido conheci- 
mento de moléstias incidentes em determinadas áreas geográficas e relacionadas com a influência de circunstâncias cliináticass, sociais e econômicas, além de outras.

Ao término dêstes comentários, apresentamos sugestão de roteiro que poderá ser seguido quando processo febril de natureza indeterminada estiver em foco. A seqüência assinalada, acreditamos, proporcionará alguns êxitos e está baseada em acúmulo de experiência que adquirimos acêrca da questão.

1 - Convirá internar c paciente em instituição hospitalar dotada de convenientes recursos, para que cuidadosa observação e os devidos procedimentos diagnósticos sejam executados. Essa forma de agir é prudente e objetiva, permitindo a coleta de múltiplas informações úteis. Até mesmo deduções simplistas advêm dessa medida preliminar, como a constatação de não persistência das elevações térmicas.

2 - Execução de enquadramento biológico imediato, mediante realização de alguns exames subsidiários fundamentais: hemograma, análise de urina e apreciacão radiológica torácica, entre outros que - tipo de problema médico sugerir. Em têrmos práticos, essas três modalidades de avaliações complementares, ao lado da determinação da velocidade de hemossedimentação, da intradermorreação de Mantoux, da hemocultura e da eletroforese das proteínas sẻricas, precisam ser sistemàticamente providenciadas.

3 - Elaboração de minuciosas anamnese e exame clínico, nessa fase em que os responsáveis pela elucidação do caso já estão em condições de obter detalhes mais concretos e da maneira bem definida.

4 - Enquadramenio biológico imediato, com avaliação de funções circulatória, renal e hepática, por exemplo, através de métodos apropriados, além de determinacões relativas a componentes protéicos, incluindo a mencionada eletroforese, imunoeletroforese, a dosagem da muccproteína sérica e as provas de labilidade proteíca; entre outras deduções, ficará definida a vigente reação do sôro, de caráter agudo, crônico ou inerte.

5 - Enquadramento caracterizável como focal, quando infecçōes localizadas, tais como sinusite ou de ordem odontológica, por exemplo, merecerão a devida atençāo.

6 - Realização de várias hemoculturas, repetidamente, com o emprêgo, sempre que possivel, de diferentes meios de cultivo bacteriano. A apregoada superioridade da utilização de sangue arterial não é aceitável sem restrições, segundo a análise que tivemos a oportunidade de efetuar sôbre o assunto.

7 - Manutenção do paciente sob cuidadosa observação, scm preconização de terapêutica específica e só agir de forma diversa quando eventual período de espera fôr capaz de condicionar o aparecimento de efeito danoso. A respeito dêste item é bem aplicável, cremos, o comentário que costumamos frisar, de que o tempo, em determinadas condições, é a quarta dimensão da doença.

8 - Utilização de técnicas diagnósticas mais especializadas, como a linfografia e qutros processos radiológicos, sendo que métodos cruentos em certas circunstâncias tornar-se-ão indicáveis, figurando entre êles a laparoscopia, a mediasterioscopia e a laparotomia exploradora, de eficiência maior que o primeiro dos procedimentos endoscópios citados, mas não usada sem ressalvas, comumente, por muitos cirurgiōes, pelo menos entre nós.

Em virtude de dificuldades expressivas, decorrentes de muitos fatôres, é necessário destacar que nem sempre advirá esclarecimento diagnóstico como decorrência do seguimento de um roteiro tão trabalhoso como o referido, em coerência com o apaixonante e, opostamente, desnorteante problema da febre de origem indeterminada.

A iniciativa de incluir considerações "sôbre o problema relativo à febre de origem indeterminada em compêndio fundamentalmente destinado a prestar orientação de caráter terapêtutico parece-nos auspiciosa. No entanto, os aspectos que anteriormente, de forma resumida, abordamos, dizem respeito sobretudo a questões de ordens conceituais e normativas e, também, afiguram-se discretamente norteadores. Não ficaram, então, estritamente, ditadas especificações referente a tratamentos, pois o tema, acima de tudc, envolve a necessidade de salientar a importância de agir corretamente, dentro de parâmetros apropriados. É fácil compreender que 
assunto tão amplo e de abordagem realmente dirícil requer, como meta prioritária, conveniente conceituação e não pode merecer abordagem à base puramente de indicações de natureza terapêutica.

Primordialmente, em circunstâncias não excepcionais, é preciso estabelecer o diagnóstico da afecção em causa, mediante adoção de condutas adequadas, realizando seguras correlações clínico-laboratoriais e evitando, sempre que possível, a execução de testes medicamentosos e de tratamentos, simples ou complexos, às cegas. Assim, as facêtas especificas de ordem curativa devem ter lugar depois da cuidadosa análise dos problemas em foco. 